\title{
Challenges in the adoption of mobile information communication technology (M-ICT) in the construction phase of infrastructure projects in the UK
}

Eloise Atkinson

Laing O'Rourke, London, UK

John Spillane and Jim Bradley

Faculty of Science and Engineering, University of Limerick, Limerick, Ireland, and

Tara Brooks

Queen's University Belfast, Belfast, UK

\begin{abstract}
Purpose - The purpose of this paper is to investigate the challenges faced with mobile information communication technology (M-ICT), more specifically tablet software, in the construction phase of UK infrastructure projects. Quality assurance in the context of passive fire protection is scrutinised, where M-ICT use is prevalent, to provide an industry perspective.

Design/methodology/approach - The research design is founded on exploratory multiple case study approach. Specific themes are developed, based on a critical review of previous ICT studies. The themes identified are used to inform a qualitative interview protocol for investigating three large UK infrastructure projects. Each project is at different stages in the construction phase, with varying examples of M-ICT implementation in use. Participants are interviewed regarding their experiences of the implementation of M-ICT on each project.

Findings - Findings identify diverse experiences across each project. Single and multiple M-ICT platforms are currently being used, with individual stakeholders using ICT in isolation, and in some instances, multiple project stakeholders are using it together. Complete replacement of paper-based processes is evident in one case study, but more commonly, digital technology is being used in parallel to traditional paper-based processes. The challenges, although varied across each case study, can be categorised under the themes of Technology (IT support, ICT infrastructure, IT security, contractual, software), People (social aspects, user competency, safety), Technical Compliance (technical compliance evidence) and Process (conventional processes).

Originality/value - It is recommended that each theme be reviewed at project commencement, with all key stakeholders, to ensure key aspects are considered prior to M-ICT deployment. This will ensure avoidance of challenges reported and maximise the opportunities that are available through M-ICT in a multi-stakeholder infrastructure project.
\end{abstract}

Keywords Construction 4.0, Process improvement, Tablet software

Paper type Research paper

\section{Introduction}

Communication and information sharing has rapidly evolved from traditional paper-based exchange to an increasingly digital and globally connected environment. However, such change can be unwelcome and disruptive to the industry norm. The construction sector

(C) Eloise Atkinson, John Spillane, Jim Bradley and Tara Brooks. Published by Emerald Publishing Limited. This article is published under the Creative Commons Attribution (CC BY 4.0) licence. Anyone may reproduce, distribute, translate and create derivative works of this article (for both commercial and non-commercial purposes), subject to full attribution to the original publication and authors. The full terms of this licence may be seen at http://creativecommons.org/licences/by/4.0/legalcode
Challenges in the adoption of M-ICT 
IJBPA 40,3 provides an example of this and, as a result, has been slow to adopt disruptive digital technologies. McKinsey and Company (2017) report that the construction sector has the lowest digitalisation rate of any industry in the UK. In amplifying this, the industry also continues to suffer from the lowest productivity growth $(0.5 \%)$ of any UK sector (HM Government, 2017).

The UK Government seek to address this productivity deficit by setting the industry targets to be achieved by 2025 . These include reduction of costs by $33 \%$ and improvement of delivery speeds of 50\% (HM Government, 2013). McKinsey and Company (2017) suggest that adoption of best practice use of technology alone could offer the industry up to a $15 \%$ productivity improvement and 6\% cost saving. However, there are many inherent barriers to the industry's uptake of technology. One such barrier is a low level of investment. Less than $1 \%$ of construction firm's revenue is currently spent on research and development (R\&D) and technology. In comparison, the aerospace and automotive sectors invest up to $4.5 \%$ of revenue and have experienced long-term gains (McKinsey and Company, 2017). The construction industry remains heavily reliant on paper-based methods of data capture and information exchange on construction sites (Abanda et al., 2018; Azhar et al., 2015). Such paper-based processes are labour-intensive, unreliable and susceptible to costly delays and unsustainable, given the amount of paper used to manage and coordinate such projects. It is proposed that information communication technology (ICT) can help address the need for disruptive change in how the industry manages communication.

\subsection{Information communication technology in construction}

ICT is an all-encompassing term relating to any product that stores, retrieves, manipulates, transmits or receives information electronically (Mutesi, 2011). The specific focus of this study is on mobile ICT (M-ICT) or tablet software, as a disruptive technology, in replacing unsustainable traditional paper-based site processes. The gains of such technology are far reaching, including how "mobile computing has been employed to manage data, improve project efficiency, reduce cost, minimise risk, and develop new construction processes" (Alsafouri and Ayer, 2018, p. 176). Tablets can be used in construction for mundane administrative tasks but can also be harnessed for truly innovative purposes, like collecting data for photogrammetry, programming and controlling drone flights, and the deployment of augment and virtual reality, amongst other tasks on-site.

However, the introduction and acceptance of any disruptive technology such as M-ICT brings with it a set of requirements and challenges, particularly when this occurs in the construction industry, renowned for its tardiness to change and continued use of traditional methods. In such a setting, it is important that the current position and the challenges are taken into account and integrated into policies and procedures supported by senor figures who will champion and appropriately resource the technology.

\subsection{Quality assurance}

The medium in which M-ICT is applied in the construction sector in this study, to assess its use in practice, is in the context a disruptive technology for augmenting the quality assurance function on projects. Quality assurance is described as a set of activities whose purpose is to demonstrate that an entity meets all quality requirements, usually when a product is finished to increase the confidence of both customers and managers. (March, 2017), especially as the industry continues to experience problems with non-compliant installation, causing rework and delay, which can result in as much as $5 \%$ of construction costs (Hwang et al., 2009) and adds to the sectors already unsustainable levels of waste generation. Furthermore, quality assurance also involves a large amount of data as it includes "inspection and testing, nonconformance reporting and corrective action taken during the construction phase" (Martínez- 
Rojas et al., 2016, p. 10), thereby providing an appropriate base on which to apply the findings. To apply and assess the results of quality assurance using M-ICT, passive fire protection practices are used.
Challenges in the adoption of M-ICT

\subsection{Aim of the study}

Based on this, the aim of this paper is to investigate the current industry practices and use of M-ICT in capturing and managing construction quality assurance information, in the delivery phase of UK infrastructure projects, in the context of passive fire protection with the intention to assist the industry in its migration from a paper-based approach, to one which is founded on M-ICT in the management and transfer of information, both on and off-site. In doing so, this will result in disruption to the sector, but such innovative initiatives are warranted, given the unsustainable use of paper-based processes in the industry. To achieve this, a qualitative multiple case study research design is applied. Three live UK infrastructure projects are identified as case studies. The criteria of selection include use of different M-ICT approaches and projects at varying phases of their construction programme, with the availability of four to five project participants for each case study. This provides a broad representation of different stakeholders, offering a wide range of perspectives and experiences of M-ICT implementation in practice. The results of this study are of benefit in the identification of the key barriers in the application of M-ICT in industry, thus aiding practitioners to acknowledge potential issues in the adoption of such practices and subsequently, provide mitigating measure in place, to counteract their negative impact in the implementation of M-ICT in the sector. However, such benefits are not without difficulties, and care must be taken to ensure that the benefits are realistically achievable with the implementation of any disruptive technology (Love et al., 2020), and M-ICT is no different.

\section{M-ICT adoption in construction: a literature review}

The adoption of technology, especially a disruptive technology such as M-ICT, on construction sites is a challenge, due to the "physical environment the technology must operate in, multiple stakeholders collaborating on and off site and the technical content communication transfers" (Rimmington et al., 2015, p. 1,368).

\subsection{Challenges to M-ICT on construction sites}

In the context of Building Information Modelling (BIM) ICT adoption in construction, Tulenheimo (2015) identifies 23 aspects that can prevent its successful implementation. These are grouped around five categories: "Customer", "Company", "Social Aspects", "Technology" and "Supporting Elements". The study's findings emphasise that for BIM technology, "successful implementation must take a socio-technical approach because it is equally reliant on the people and processes as it is the technology" (Tulenheimo, 2015, p. 469), a sentiment echoed by Araycic et al. (2010). Tulenheimo (2015) argues that all factors must be considered and appropriate tools chosen to avoid partial success. Support from all levels within the organisation is paramount, while specifically adequate technical resources and ICT support is also required.

In contrast, Oesterreich and Teuteberg (2016) adopt a different approach to investigate challenges. They conduct a systematic literature review of publications from the last 10 years and define Industry 4.0 as an alternative means of describing the construction sectors increased use of ICT in addition to other manufacturing technologies. Their results are triangulated with findings present in published case studies. Three clusters of Industry 4.0 concepts emerge: "Smart Factory", "Simulation and Modelling" and most importantly "Digitisation and Virtualisation" (cloud computing, big data, mobile computing, social media 
IJBPA 40,3 and digitisation). This study opted for the PESTEL (Political, Economic, Social, Technological, Environmental and Legal) framework for reviewing and combining findings, outlining the benefits and challenges found in the Industry 4.0 literature. Findings from this research represent challenges or issues that should be addressed to allow the adoption of Industry 4.0 ICT. Oesterreich and Teuteberg (2016) cite enablers for adoption of ICT including staff training to increase competency, in addition to advice to government to mandate the use of ICT, incentivise adoption and provide R\&D funding. A literature review specifically in the context of M-ICT - "Mobile Computing in the Construction Industry: Main Challenges and Solutions" (Silverio et al., 2016) outlines risks associated with the implementation of mobile computing. This review highlights the risks of adoption of mobile computing, which include "information security", "privileged user access", "regulatory compliance", "data location", "availability" and "disaster recovery".

In an alternative research approach, Azhar et al. (2015) apply an industry survey and cite the main encumbrance to widespread adoption of M-ICT is software that is not fit for purpose, lack of parent company backing, top management commitment, management process change coupled with an increase in cost due to training and hardware/maintenance costs, software licencing fees, plus the presence of connectivity issues and interoperability issues. In common with Oesterreich and Teuteberg (2016), Azhar et al. (2015) advise that strong training programmes to familiarise M-ICT users with the full functionality and benefits are required to encourage uptake of M-ICT. Harstad et al. (2015) echo the requirement for guidance and training, while also advising pre-deployment M-ICT useability assessment, with testing through the use of pilot projects and "success stories" promoted, to increase successful and widespread M-ICT adoption.

In contrast, Sattineni and Schmidt (2015) conclude that for companies to reap the maximum benefit from M-ICT, they must fully invest and keep updated with the latest software to ultimately result in productivity improvements. Sattineni and Schmidt (2015) carried out 12 qualitative interviews with construction managers and IT specialists from US construction companies. This alternative research methodology results in divergent findings from other studies. Obstacles to M-ICT uptake within the construction industry referenced in the interviews include "older workers", "steeper learning curve", "lack of time for training", "resistance to change", "not everybody needs the devices", "not all capabilities used by workforce", "cost of applications" and "older workers reluctant to adopt these devices".

\subsection{Potential of M-ICT on construction sites}

An empirical study on an Australian construction site by Matthews et al. (2015) presents a re-engineered process of monitoring real-time progress management of reinforced concrete frame construction using an M-ICT cloud (BIM 360 Field)-based system. The study cites challenges with data transfer (interoperability problems) in terms of manually moving information captured on site via M-ICT devices to a useable structure (Microsoft ${ }^{\mathrm{TM}}$ Excel $^{\mathrm{TM}}$ ), for the planner to feed into existing software (and comply with the existing process, compliant to ISO 9001). However, despite this challenge, there was enthusiasm and positive feedback from the site team, eager to extend the scope of the cloud-based BIM using the M-ICT trial, specifically the possibility of digitalising the quality process. The site team requested features including access to project documents, ability to digitally mark-up onsite and digitalising quality assessment checklists to allow completion on M-ICT devices. This provides office staff instant access, in addition to the possibility of attaching photos to BIM objects, to record and communicate progress. Interestingly, this demonstrates that despite the challenges that are faced with implementation of M-ICT, construction site staff are eager to move to a digital working environment as they recognise the efficiencies and benefits. 
In a recent UK study, Abanda et al. (2018) investigate the "potential of cloud/mobile BIM for the management of construction projects" to specifically understand the different cloud/ mobile BIM technologies being used in practice. This research is limited to an online questionnaire of BIM professionals and predetermined factors are probed. The findings, while not statistically analysed, are validated with a limited number of interviews (four consultants, one building contractor, all working for companies of more than 250 people in Oxford, UK). The cloud/mobile BIM technologies studied include collaborative purposes (being the most prevalent reason for use) and to remotely view and exchange data over wireless networks using mobile devices. Challenges include "lack of skills and competence", "data ownership concerns", "confidentiality" and "lack of trust". Enablers documented are access to unlimited data, reliable Internet access and standardised or interoperable file formats.

\subsection{M-ICT and passive fire protection}

Passive fire protection is defined as "built-in measures that protect the structure of the building and subdivide it into areas to limit the spread of fire" (ASFP, 2019). The justification to focus on passive fire is made for three reasons. First, studies by Liu et al. (2017) report on the productivity improvements that can be achieved through M-ICT, but to date, no research has been reported on passive fire protection, where there are multiple interfaces in personnel and construction processes. Second, the passive fire trade has been observed as early adopters of M-ICT. Third, the importance of passive fire protection as a topic for investigation has been highlighted by the Grenfell tragedy and Dame Judith Hackett's (2018) subsequent report - "Building a Safer Future - Independent Review of Building Regulations and Fire Safety: Final Report”. One of Hackett's (2018) key recommendations is a requirement for "Transparency of information and an audit trail [...] all the way through the life cycle of building, from the planning stage to occupation and maintenance is essential to provide reassurance and evidence that a building has been built safe and continues to be safe" (Hackitt, 2018, p. 6).

\subsection{M-ICT and sustainability}

From a sustainability perspective, construction has a negative impact on the environment, from the production of materials, their transport to site, incorporation into the fabric of the project and finally, as waste material once end-of-life has been reached. In the UK, $32 \%$ of landfill waste and $25 \%$ of all used raw materials are due to construction activity (Prism Environmental, 2012) with the EU reporting that construction waste accounts for 25-30\% of all waste generated in the region (European Community, 2015). In their 2020 paper, Lekan et al. (2020) outlined the contribution disruptive technologies and Industry 4.0 with their ability to move construction to a more sustainable footing. The recognition of the importance of digitisation in delivering sustainable development and for delivery of competitive advantage through process improvements are also important factors to consider (Faller and Feldmuller, 2015).

To address this and focussing on the use of M-ICT, a very particular type of waste can be reduced on a construction project - paper waste. During a construction project, a significant amount of paper is used to capture and disseminate the information required. Paper is the "traditional" way to distribute information, yet it is subject to many problems on a construction site - it can get lost, damaged, become illegible, require duplication, lack currency, need storage space and be hard to access if working remotely. From a sustainability viewpoint, production of a single sheet of A4 paper requires 10 litres of water and at end-oflife, if it ends up in a landfill, it produces methane and if it is burnt, it produces carbon dioxide, both of which are greenhouse gases (Timico, 2018). The introduction of M-ICT removes or at 
IJBPA

40,3

\section{2}

least reduces the need for paper, thereby eliminating the problems associated in its use in communication, but more so, reducing paper waste and averting the sustainability issues associated.

When moving onto assessing M-ICT in this context, and to allow comparison of all challenges identified across previous studies, themes have been identified, grouped around first orders categories as presented by Pas et al. (2017) in their study "Overcoming ICT Barriers in IBS Management Process in Malaysia Construction Industry". These include "People", "Technology", "Process" and "Technical Compliance" and are the basis on which this paper is developed. These all feed into and are dependent upon four factors as identified by Hasan et al. (2019) - improved communication and information flow, better project execution, improved access to data and proper defect management. The ability to enable collaboration and information flow across the four categories outlined above should be the purpose of utilising M-ICT to enhance construction project management (Oesterreich and Teuteberg, 2016) leading to the improvement of quality and reduction of waste.

\section{Research design}

As outlined in the literature review, barriers to the adoption of ICT in construction are many and varied. To get an industry perspective of such barriers in the context of M-ICT, a case study approach is adopted to ascertain actual barriers documented by those who are tasked with using such systems and processes. The case study method adopted is described by Yin (2014), which includes three distinct phases, Phase 1: Design Study, Phase 2: Single Case Data Collection and Analysis and Phase 3: Cross Case analysis (see Figure 1).

\subsection{Phase 1: design study}

The initial step of the research involves a comprehensive review of the literature. Comparable studies have explored similar topics using varying methodologies, within different geographic locations or different specific contexts, none of which investigate the application of M-ICT from a UK perspective in the context of large infrastructure projects.

Investigation of three case studies is established as an appropriate quantity to study, giving an opportunity to demonstrate replication as well as rival theories (Yin, 2014). This number also provides an opportunity to triangulate the results obtained. Furthermore, to gain

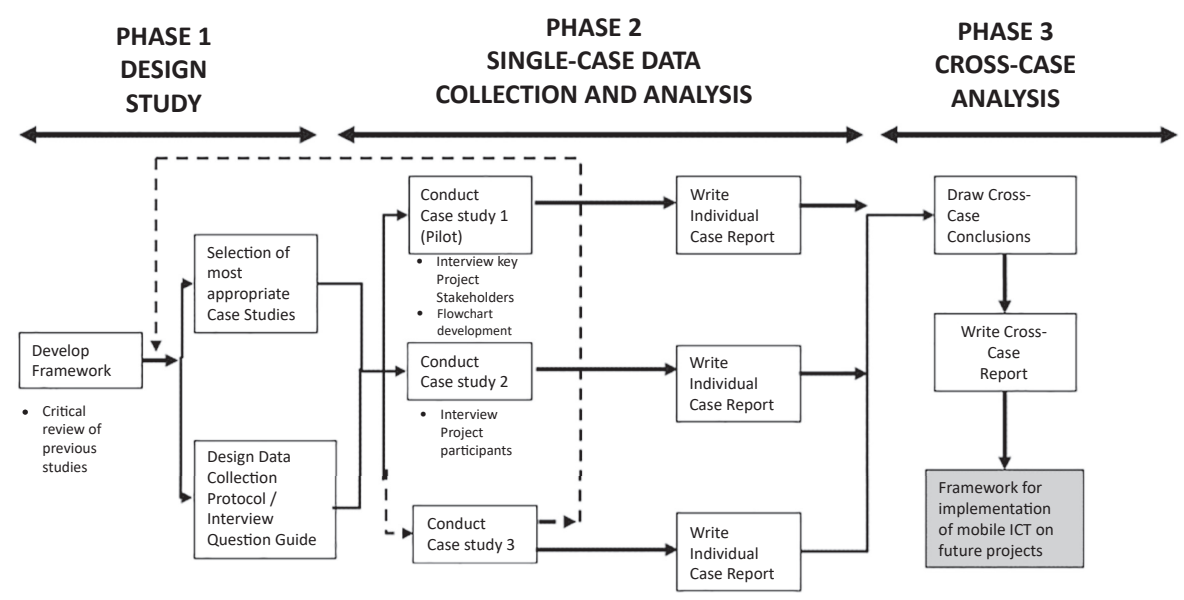

Figure 1.

Research outline process as per Yin (2014) 
insight at each stage of a project, three case studies were identified; each addresses the early, middle and late-stage completion. The case studies included in the study are identified using various selection criteria, which were developed to ensure the most appropriate infrastructure projects are selected to meet the research aim. The selection criteria decided the adoption of M-ICT by the research team include the following:

(1) UK Infrastructure Project of $£ 200-£ 500 \mathrm{~m}$ in value.

(2) Construction phase of project.

(3) Passive fire protection package of works to the value of greater than one million pounds.

(4) Extensive use of one or more M-ICT tools in management of the passive fire protection operational and quality assurance activities.

(5) Willingness of stakeholders to participate in interviews.

(6) Minimum of two project stakeholders represented in the interviews (projects with greater number given priority).

(7) Minimum of four varying project participants willing and available for interview to discuss their experiences.

Once prospective projects based on the selection criteria outlined above are identified, senior decision makers on these projects are then approached directly to gauge amiability to participate in the study. Several senior managers declined to participate for varying reasons, such as no use of M-ICT on-site, limited time commitments available or already participating in another study.

This stage is followed by an initial informal telephone screening, which is conducted with the project's passive fire protection package manager to ensure the case study suitability against the selection criteria and that the participants are willing to be interviewed. The three most suitable case studies, based on the criteria outlined above, are then selected to proceed with the study, ensuring variation between projects (that is, project stakeholder organisations, phase of the construction project, software being used, parent organisation sponsorship and extent of stakeholders using system).

As the study is primarily examining the user's experiences of the mobile software in a real project environment, participants who are using the M-ICT, either directly or using the data captured, are deemed the most suitable to interview. As the study is bound in the context of passive fire protection, this further refined the pool of eligible interviewees on each project. It is suggested that all project stakeholders who are involved with implementation and use of M-ICT in the context of passive fire protection to be interviewed regarding their experience and thoughts. The study intends to ensure that it involves "interviewing key persons [different shareholders] representing different perspectives to develop a fuller picture of the situation" (Proverbs and Gameson, 2008, p. 102). The suggested "non-exhaustive" list included for consideration for interviewees includes the following:

(1) Main contractor (package manger, project manager, construction manager, engineer).

(2) Passive fire protection subcontractor (project manager, site supervisor, operatives).

(3) Design fire engineer.

(4) Verification fire engineer.

(5) Third-party fire assurance inspector. 
IJBPA

40,3

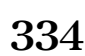

(6) Any others as advised by project participants as being involved and suitable to interview.

The interviews are conducted, ensuring ethical research practices as described by Creswell (2014). Interviewees are given a participant information guidance document, both in advance of the interview and again prior to the interview being conducted, which details the purpose of the research, why they had been chosen to participate and principles of confidentiality including anonymity of data, as well as the right to refuse participation at any point of the study. The research data are stored in accordance with data protection laws, including in a password-protected file on a password-protected computer. At the close of each interview, the interviewee is asked to advise whether there are any other appropriate project stakeholders that they would suggest for interview, ensuring all relevant case study participants are included in the study. To maintain confidentiality and anonymity, each participant is assigned a code, for example, C1-A, which corresponds to "Case Study 1-Participant A". The details for each case study are in Table 1.

\subsection{Phase 2: single case data collection and analysis}

A comprehensive case study protocol was developed to ensure reliability and repeatability of the research. This study uses a single source of evidence; interviews with project stakeholders, as it specifically looks to understand project stakeholders' lived experiences regarding challenges with use of M-ICT. Proverbs and Gameson (2008, p. 102) advise interviews "represent a very important aspect of case study research and are used to fully understand someone's impressions or experiences".

The study investigates M-ICT in the context of passive fire protection in the construction phase of infrastructure projects, which is a previously unexplored area. The design of the interviews is adapted from previous research exploring ICT in a new context (Kasim, 2011; Davies and Harty, 2013). The interviewer guide uses open-ended and broad questions, which allows interviewees to speak freely about the challenges they meet using M-ICT on their specific project case study. The questions are simple, specific, individual, exhaustive and nonbiased. The interview guide is first tested using a pilot exercise and revised following feedback from the pilot interviewees.

Following development of the case study protocol and interview guide, each case study is conducted sequentially. To ensure balance and equity between cases, all interviews are conducted by the same researcher across every case study, thus minimising differing approaches or interpretations which may arise where two or more interviewers undertake the process. Case study projects are visited, and interviews conducted in situ over a two-day period, capturing the information using short-hand notetaking, in addition to audio recording. Semi-structured interviews provide the interview structure, following the interview Question Guide as outlined in Table 2, while allowing the flexibility for the interviewee to speak freely about their experiences. Four to five interviews are conducted on each project and interviews last 45-60 min. Interviews are fully transcribed verbatim to allow for subsequent analysis. Following each case study, a descriptive account is also recorded, as per Eisenhardt (1989), to assist in the data extraction exercise.

The interviews generate in-depth, rich qualitative information and data. To allow analysis of these data, first, data reduction is carried out on the raw transcript from the interview, which includes tabulating the interview in Microsoft ${ }^{\mathrm{TM}} \mathrm{Excel}^{\mathrm{TM}}$, placing specific sentences in each cell and removal of any repetitive data. Thematic coding is then undertaken on each interview in the form of mind-mapping, where using both the audio transcripts and the interviewer's annotated remarks from the interview, factors are catalogued under the themes identified in the literature review; "Technology;" "Process;" "People" and "Technical Compliance". Broad first order codes are pre-set before data collection although suborder codes within these emerge from 


\begin{tabular}{|c|c|c|c|c|}
\hline $\begin{array}{l}\text { Case study } \\
\text { number }\end{array}$ & $\begin{array}{l}\text { Stage of } \\
\text { passive fire } \\
\text { works }\end{array}$ & Project works & Interviewees & $\begin{array}{l}\text { Challenges in } \\
\text { the adoption of } \\
\text { M-ICT }\end{array}$ \\
\hline \multirow[t]{2}{*}{1} & \multirow[t]{2}{*}{ End-stage } & \multirow[t]{2}{*}{$\begin{array}{l}\text { Construction and fit out of a tunnelled underground } \\
\text { station, two ticket halls and back of house building } \\
\text { Location: London }\end{array}$} & \multirow{2}{*}{$\begin{array}{l}\text { 1. Site supervisor } \\
\text { (C1-A) } \\
\text { Passive fire } \\
\text { subcontractor } \\
\text { 2. Project manager } \\
\text { (C1-B) } \\
\text { Passive fire } \\
\text { subcontractor } \\
\text { 3. Project manager } \\
\text { (C1-C) } \\
\text { Main contractor } \\
\text { 4. Fire engineer } \\
\text { (C1-D) } \\
\text { Fire verification } \\
\text { consultancy } \\
\text { 5. Fire inspector } \\
\text { (C1-E) } \\
\text { Third party }\end{array}$} & 335 \\
\hline & & & & \\
\hline 2 & End-stage & $\begin{array}{l}\text { Construction of new underground stations, } \\
\text { platforms, shafts plus ancillary works to services } \\
\text { for London underground } \\
\text { Location: London }\end{array}$ & $\begin{array}{l}\text { 1. Package manager } \\
\text { (C2-A) } \\
\text { Main contractor } \\
\text { 2. Construction } \\
\text { manager (C2-B) } \\
\text { Passive fire } \\
\text { subcontractor } \\
\text { 3. Site supervisor } \\
\text { (C2-C) } \\
\text { Passive fire } \\
\text { subcontractor } \\
\text { 4. Project manager } \\
\text { (C2-D) } \\
\text { Passive fire } \\
\text { subcontractor }\end{array}$ & \\
\hline 3 & Mid-stage & $\begin{array}{l}\text { Construction of new build and refurbishment } \\
\text { works to a local hospital } \\
\text { Location: South-east England }\end{array}$ & $\begin{array}{l}\text { 1. Package manager } \\
\text { (C3-A) } \\
\text { Main contractor } \\
\text { 2. Construction } \\
\text { manager (C3-B) } \\
\text { Main contractor } \\
\text { 3. Site supervisor } \\
\text { (C3-C) } \\
\text { Passive fire } \\
\text { subcontractor } \\
\text { 4. Senior fire } \\
\text { engineer (C3-D) } \\
\text { Fire verification } \\
\text { consultancy } \\
\text { 5. Project director } \\
\text { (C3-E) } \\
\text { Main contractor }\end{array}$ & $\begin{array}{r}\text { Table } 1 . \\
\text { Case study details }\end{array}$ \\
\hline
\end{tabular}


IJBPA 40,3
Case study interview question guide

\begin{tabular}{ll}
\hline Name & Interview code \\
Job role & Date \\
Organisation & Time \\
Project & Duration
\end{tabular}

\section{6}

Project context questions

Section 1 - M-ICT details and implementation

Q1 What M-ICT is being used in relation to passive fire protection?

Q2 What is the main purpose the ICT is being used on this project and is used in conjunction with other M-ICT or paper processes?

Q3 How it the ICT being used on this project and who is using or has access the ICT? (Inspections, information captured, information shared and anything else) DEMONSTRATE/MAP IN FLOW DIAGRAM

Q4 How were the forms and processes of using the M-ICT developed on this project and who was involved? Section 2 - Benefits and changes to work practices

Q5 What benefits or advantages have you experienced on the project from the implementation of the M-ICT?

Q6 What benefits or advantages have you experienced on the project from the implementation of the M-ICT for QA? (If anything, additional to Q5)

Q7 Have you experienced any changes to communication or construction practices with the implementation of the M-ICT on this project?

Q8 In an overall sense on this project how effective have you found using the ICT for QA capture and management?

Section 3 - Challenges experienced, future adoption enablers and trends

Q9 How have you found the tablet to use, foremen friendly?

Q10 Please describe any challenges you have experienced with the implementation and use of M-ICT on this project?

Q11 Please describe any challenges you have experienced with using the M-ICT for in a QA sense on this project? (If anything, additional to Q10)

Table 2.

Interview question guide
Q12 Do you have any advice for future projects implementing and using M-ICT for passive fire protection?

Q13 Can you recommend anyone else involved with the use of M-ICT and passive fire protection on the project that what be suitable to interview about their experiences?

the data. To validate the interpretation of interview findings, the coded tabulated version of the transcript is shown to the interviewees, post-interview, to affirm and validate the accuracy of the information contained within and the subsequent analysis undertaken. Following individual analysis, the case study as a whole is tabulated together (Eisenhardt, 1989) to obtain a full understanding of the project, where all perspectives and experiences are included. This information is then transferred to a pictorial mind map, which allowed the data to be interpreted, patterns to be identified and relationships to be inferred. Interviewees with similar project job roles, such as installers, manager and fire review, are colour-coded to allow further interpretation of results in the mind maps developed.

\subsection{Phase 3: cross case analysis}

Following individual case analysis, cross case comparison is conducted between case studies to provide key findings, while identifying similarities and differences between each. The use of mind maps aids the ability to observe common threads and points of difference, thereby providing a supplementary visual aid to the detailed text transcripts. The visual comparison of mind maps allows immediate distinction of similarities and differences between case studies. The findings are also compared to the literature to identify areas of conformance and contradiction between both sources of information. This, in conjunction with interviewee 
comments, aids in the development of the subsequent discussion, while providing factors of merit to conclude the work.

\section{Case study: results and analysis by theme}

Challenges experienced with the use of the M-ICT on each of the case studies, while varied, are extensive and report around four key themes identified in the literature review: "Technology;" "Process;" "People" and "Technical Compliance". Figure 2 documents each of the themes, the factors identified and the associated challenge they present to those who are tasked with managing the M-ICT, high, medium or low challenge, based on the perception of the interviewees and their respective case study.

\subsection{Technology}

Challenges around technology are discussed in depth, with reference made to "IT security;" "IT Support;" "ICT Infrastructure" and "Software", including bugs, data synchronisation, customisability and capability. Interviewee C1-A notes the "wrong system" was used. Specifically, the interviewee refers to challenges such as "capability" of the software, with no multi-user access to the system, data access and data output restrictions. Overall, Case Study 1 reports the most challenges across all categories, particularly with technology, suggesting that the M-ICT itself was not appropriate for the application. This mimics Tulenheimo (2015, p. 469) "Without [...] suitable tools, totally successful implementation is difficult to realise although partial success stories can be achieved".

In Case Study 2, limited challenges around technology are reported; however, the main issue described in all interviews on this case study is the lack of vendor support. This is a significant issue within the organisation, such that the system is almost abandoned. A further challenge that Interviewee C2-A raises is the frustration of not having direct access to the subcontractor system; it is not known if this is a privacy issue or due to lack capability of the software to have "Privileged User Access", thus allowing visibility of only certain information. In Case Study 2, interviewees note that this may be attributed to M-ICT being applied in the early stages on the project.

In Case Study 3, technology challenges are mostly the result of the large volume of data being captured and managed. The lack of connectivity on-site causes the system to run offline, relying on the device's hardware storage capacity, resulting in three device upgrades

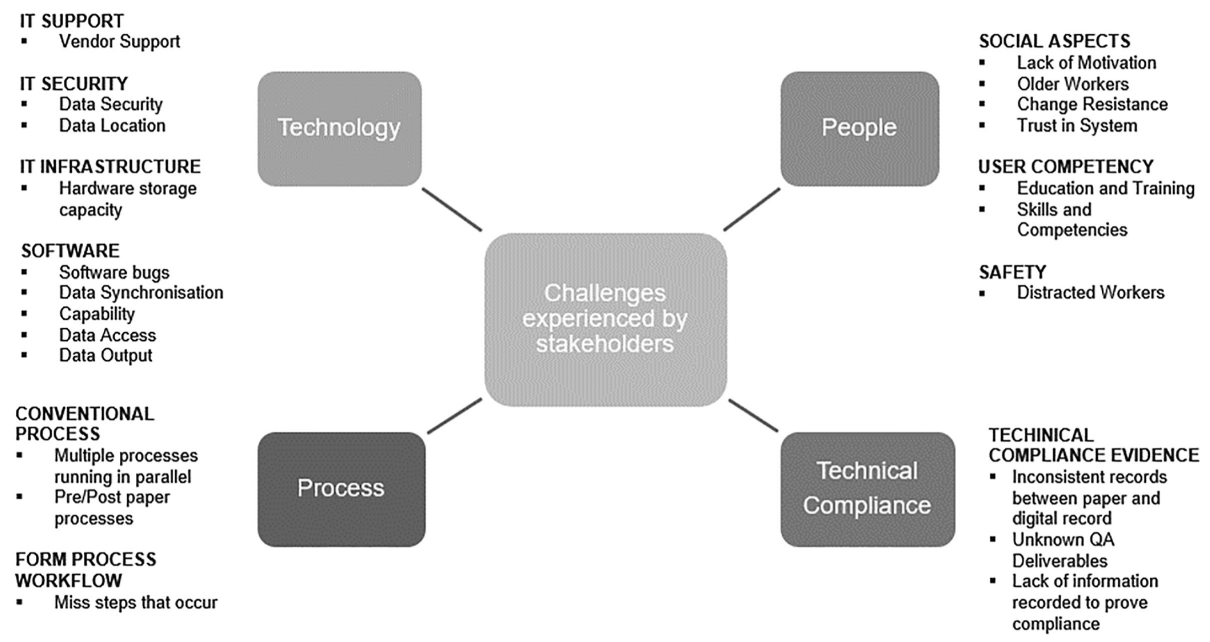

Challenges in the adoption of M-ICT 
IJBPA

40,3

338
(16 GB, $32 \mathrm{~GB}$ and $128 \mathrm{~GB}$ ) and causing data synchronisation issues. On reflection, the team advise this could have been resolved had they originally split the project into sub-projects, limiting the data requirements for each. The capability limitations of the system employed are also uncovered. Data output restrictions prevent all captured quality assurance form data from being extracted from the system into a useable format (in this case a spreadsheet), which inhibited data analysis and workflow management, in the form of status updates and reporting, amongst others. This limitation results in the need to manually transpose information from forms into spreadsheets, reported to be a full-time job for the team to manage the data. It is also noted that the disadvantage of the system operating offline results in communication between site and office being delayed and/or out of sync. The team advise it would have been advantageous to communicate and problem-solve instantaneously, instead of waiting until the following day once data synchronisation had occurred.

Interestingly, all case studies report issues with "IT Vendor Support" and "Software Bugs", however, with varying severity. Case Study 1 and Case Study 3, both running offline systems with large amounts of data, commonly report "hardware capacity" and "data synchronisation" challenges. They also share problems with "Data Output" limitations, resulting in significant backend data manipulation. Matthews et al. (2015) cite similar challenges with site-captured data being heavily manipulated before its next use, thus providing further challenges to its adoption.

\subsection{Process}

All interviews covered, to some extent, the frustration of running paper-based systems in parallel to the M-ICT; for example, completing a quality assurance checksheet inspection record, in conjunction with doing so, digitally. Interviewee C1-D, a verification fire engineer, and Interviewee $\mathrm{C} 1-\mathrm{E}$ both mentioned the lack of complete data being captured and a dependence on the installer rather than the system for information on what has been installed.

Furthermore, Interviewee $\mathrm{C} 2 \mathrm{C}$ is frustrated conducting paper-based activities preceding digital record keeping, describing manual recording and spreadsheet generation that ultimately resulted in duplication of work in the digital platform as very time-consuming and that such practices are not the most efficient and sustainable use of an individual's time.

Process challenges are similar on both Case Study 1 and Case Study 3, where the system is only carrying out a single process step. Paper-based activities being carried "pre", "post" and in "parallel" are attributable to causing significant inefficiencies, driving further unsustainable practices. The process challenges with Case Study 3 centred on the digital stage process as set on the system, not addressing the site requirements. Both Mathews et al. (2015) and Ern et al. (2017) iterate the importance of process-based improvements, while indicating that where such processes are not in place, barriers evidenced in the case studies will inevitably materialise.

\subsection{People}

Issues emanating around people also come to the fore in each case study, specifically relating to "User Competency", with a lack of adequate training for all team members repeatedly referred to. A lack of awareness of the project requirements by operatives is also noted, where individuals are unaware of the level of detail required on the M-ICT. Both Interviewees C1-A and C1-D advise that this could be addressed with a comprehensive form on the tablet to generate consistency.

Several challenges are related to the implementation of the M-ICT, particularly where a new system is being deployed in a subcontractor organisation. The resulting challenges generated that have since been overcome through training and education. Resistance to change is identified in the first three to six months of Case Study 2, with the site team starting to record digitally and the office team accessing the digital records. Intensive training, 
shadowing and strong upper management support helped to overcome initial resistance to the move to digital techniques. Interviewee C2-D reports these hurdles have been overcome and describes working digitally as established company practice.

Interestingly, in Case Study 2, Interviewee C2-A admits initially having a lack of "trust in the system", requesting duplication of digital shift record sheets in paper copy. The interviewee was initially unsure whether the digital record could be tampered with after signing and was concerned as the records contained commercially sensitive evidence. This was later resolved once better understanding of the security of the ICT was understood by the interviewee.

In the context of Case Study 3, people challenges reported are minor and had been largely overcome at the time of interview. The interviewees cited concerns again with "a lack of trust in system", describing the fire engineers initially insistence that photos of their identification badge should be added with their digital sign-off to provide additional security and traceability. This requirement has since been abandoned as trust has been built within the team and good working relationships developed amongst those involved. "Resistance to change" is also cited; however, this is noted as being a generational related factor, this is managed by ensuring older staff are paired with younger members of the team to provide adequate support. "User competency" is addressed with extensive upfront training with all staff members; however, as the project progressed, Interviewee C3-A recalls that new staff joining the project have not required training; instead, they simply learnt on the job from others. In contrast, Interviewee C3-D felt there has been a lack of adequate training for new staff to ensure project requirements are understood, which has resulted in minor inconsistencies in record keeping, causing revisits on site to capture further evidence. Interviewee C3-D also considers that the introduction of regular team meetings would have been advantageous to jointly resolve minor issues with the digital records as they arose.

People challenges also include "Social Aspects" reported with Case Study 2 and Case Study 3, which both had multiple users on the system. However, these were resolved in the initial stages of using the system by training and management mandating use of the M-ICT. While "Social Aspects" are not reported in Case Study 1, this is unsurprising as a limited number of users are sharing the single device. "User Competency" problems as described in Case Study 1 and Case Study 3 focus on quality of the information captured. Interviewees reference in both cases that training on system requirements for all staff is needed to ensure consistent and adequate data capture. The importance of adequate staff training is echoed in studies by Azhar et al. (2015), Oesterreich and Teuteberg (2016) and Tulenheimo (2015).

\subsection{Technical compliance}

In Case Study 1, technical compliance difficulties are reported by all stakeholders around a "Lack of Evidence to Prove Compliance", "Unknown Quality Assurance Deliverables" and "Inconsistent Records" captured on site, which are required to enable technical compliance sign-off. This is evidenced by the comments from Interviewee C1-D relating to consistency of the information on materials used.

While the forms are used to demonstrate and sign-off technical compliance, they are also used to manage workflow process of an installed firestop. The team explain the M-ICT system is configured with a four-stage process to reflect contractual status. However, these stages do not completely reflect the true project status of works. For example, the "Stage 3" sign-off is completed by the passive fire installer when their works are complete; however, there are often other trades (MEP minor works), to be completed, prior to final compliance sign-off. This causes difficulties for the project team to manage the close-out of works and required the integration of both the M-ICT data and that of a manually generated spreadsheet.

Challenges around technical compliance were limited in Case Study 2 and Case Study 3. In Case Study 2, both the inconsistent records between paper and digital records and the lack of clarity around which paperwork was required at the end of the project (quantity and format) 
IJBPA 40,3 were referenced. In Case Study 3, reference was made to lack of clarity around which paperwork was required. Also, there was a belief that it was a contractual requirement that the joint (client, main contractor and subcontractor). Quality assurance inspection form was recorded in paper format with signatures in ink. Tulenheimo (2015) argues that technical compliance is as important as people and process improvement in the development and implementation of new technologies, particularly in the built environment.

Most technical compliance challenges are reported in Case Study 1, which at time of interview was in the final stages of the project, carrying out final technical compliance signoff; therefore, facing problems with "Inconsistent records with digital and paper" and "Lack of Evidence" being recorded on the digital system at the time of build. While many of the challenges noted are minor, challenges are identified around technical compliance, which needed to be addressed. As the team discussed these issues as the project progressed, the quality assurance forms have matured to what is deemed the required level of information to demonstrate compliance, with some at version thirteen, at the time of writing. Interviewee C3-D explains that this is a result of the industry having a "[...] lack of appreciation from a fire regulation perspective what's required to prove compliance”.

\section{Conclusion}

This exploratory multiple case study research investigates how M-ICT is being used in the delivery phase of UK infrastructure projects, in the context of passive fire protection, focussing specifically on quality assurance and identifies inconsistencies in the adoption of M-ICT, both within and across case studies. It is not uncommon for projects to operate multiple software systems in parallel, as well as completing several tasks, via the traditional paper-based method, as evidenced in Case Study 2 for example. However, one would question whether such practices were a sustainable and efficient use of resources, given the clear evidence of repetition being carried out in some of these tasks. Two varying approaches to $\mathrm{M}$ ICT adoption were identified - the first involves M-ICT being used by a single stakeholder, in this instance, a passive fire subcontractor, to create a digital record of the installation of site works. In contrast, the second approach incorporates all key stakeholders integrated onto one system, with all steps in the quality assurance process workflow (survey, design allocation, record of install, inspection of workmanship and technical compliance sign-off) completed on the M-ICT, thus eliminating all site-based paper processes. It is evident that the second approach, as demonstrated by Case Study 3, is the more advanced implementation, albeit disruptive to the norm, but with clear advantages gained.

Each of the interviewees notes several key challenges experienced on their respective case study, summarised under the themes of: Technology (IT support, ICT infrastructure, IT security, contractual, software), People (social aspects, user competency, safety), Technical Compliance (technical compliance evidence) and Process (conventional processes). To mitigate the challenges documented, future projects should adopt the use of M-ICT across reporting lines from the outset. Project participants advocate the use of M-ICT on future projects, thus further demonstrating the benefits of adopting this disruptive approach as shown in Table 3 , in developing and further refining the levels of quality assurance within the sector. To ensure consistency, project participants state that there should be up-front discussions and agreement between all key stakeholders to ensure processes for using M-ICT are clearly set out. In addition, awareness of the capability and limitations of the software, as well as consideration about follow-on use of the information captured, is required to avoid time-consuming back-end manual data manipulation.

The findings from this study have implications for industry. Implementation of M-ICT in construction is increasing from a low base and likely to meet many of the challenges identified across the case studies. To mitigate some of the challenges, the suggested actions as outlined in Figure 3 should be implemented. The findings suggest that the maturity of adoption has a 


\begin{tabular}{|c|c|c|c|c|}
\hline General benefits & $\begin{array}{l}\text { Case study } \\
1\end{array}$ & $\begin{array}{l}\text { Case study } \\
2\end{array}$ & $\begin{array}{l}\text { Case study } \\
3 \\
\end{array}$ & $\begin{array}{l}\text { Challenges in } \\
\text { the adoption of }\end{array}$ \\
\hline $\begin{array}{l}\text { Data accuracy } \\
\text { Improved site record keeping (photos, location and details of } \\
\text { install) } \\
\text { Audit trail/Traceability } \\
\text { Data analysis }\end{array}$ & D & $\begin{array}{l}0 \\
0 \\
0\end{array}$ & $\begin{array}{l}\bullet \\
\bullet\end{array}$ & 341 \\
\hline $\begin{array}{l}\text { Quality } \\
\text { Improved evidence } \\
\text { Non-compliance spotting } \\
\text { Higher standard of quality (accountability/Visibility } \\
\text { Records captured at time of build (system mandates capture of data } \\
\text { at time of build) } \\
\text { Process (compulsory staged quality review by all stakeholders) }\end{array}$ & $\begin{array}{l}0 \\
0 \\
0\end{array}$ & $\begin{array}{l}0 \\
0 \\
0\end{array}$ & $\begin{array}{l}\bullet \\
\bullet \\
\bullet \\
\bullet \\
\bullet\end{array}$ & \\
\hline $\begin{array}{l}\text { Collaboration } \\
\text { Collaborative working } \\
\text { Problem-solving } \\
\text { Communication } \\
\text { Stakeholder relationships } \\
\text { Remote working }\end{array}$ & $\begin{array}{l}0 \\
0 \\
0 \\
0\end{array}$ & $\begin{array}{l}1 \\
0 \\
0\end{array}$ & $\begin{array}{l}0 \\
0 \\
0 \\
0 \\
0\end{array}$ & \\
\hline $\begin{array}{l}\text { Construction management } \\
\text { Work task allocation } \\
\text { Progress monitoring } \\
\text { Cost tracking } \\
\text { Overall management }\end{array}$ & $\stackrel{0}{\bullet}$ & $\begin{array}{l}0 \\
0 \\
0 \\
0\end{array}$ & $\begin{array}{l}0 \\
0 \\
0 \\
0\end{array}$ & \\
\hline $\begin{array}{l}\text { Productivity } \\
\text { Information access - office } \\
\text { Information access - infield } \\
\text { Faster decision-making } \\
\text { Employee performance } \\
\text { Time saving } \\
\text { Cost saving } \\
\text { Note(s): High, } \bigcirc \text { Medium, ○ Low }\end{array}$ & $\begin{array}{l}0 \\
0\end{array}$ & $\begin{array}{l}0 \\
0 \\
0 \\
0 \\
0\end{array}$ & $\begin{array}{l}0 \\
0 \\
0 \\
0 \\
0\end{array}$ & $\begin{array}{r}\text { Table } 3 . \\
\text { Comparison of benefits } \\
\text { across all } 3 \text { case studies }\end{array}$ \\
\hline
\end{tabular}

direct influence on the overall challenges encountered, with many issues mitigated where individuals embrace and engage with the use of M-ICT across all key project stakeholders. Furthermore, the integration of all stakeholders onto one system is advantageous in enabling data capture, a digitalised streamlined process, and avoidance of inefficient duplication of processes, which encompass many of the challenges identified. In practice, this is most likely to be achieved by consideration in early project stages, for example, by forming part of contractual arrangements, as demonstrated on Case Study 3. Furthermore, the migration away from the unsustainable use of paper in the industry is needed. The advent of M-ICT is one potential avenue to reduce the reliance on paper, thus making the industry more sustainable.

Data capture requirements should be considered upfront with all relevant project stakeholders and periodically reviewed to ensure suitability for the project requirements. Overall, anticipated process of use needs to be established at the commencement of the project and should be revisited as project requirements mature. These requirements include the captured data use throughout the project life cycle, that is, demonstrating technical compliance, monitoring and reporting status of works and data analysis. The data output requirements of the system for follow-on use must be considered upfront to avoid the back-end data bottle neck, 


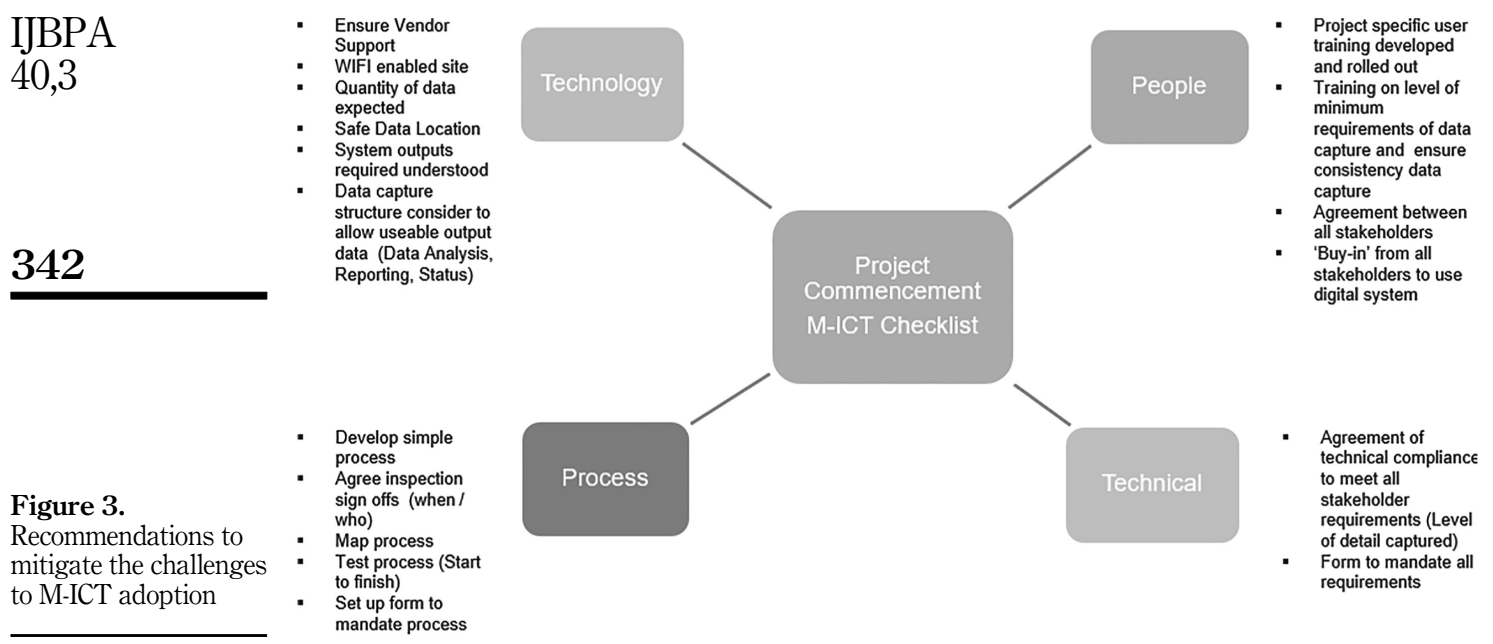

as experienced in Case Study 1 and Case Study 3. Furthermore, the issues raised about data security must also be considered, regardless of the format prescribed.

This study allows an in-depth enquiry into the application of M-ICT on three case study projects; however, the results cannot be generalised. The cases chosen are large UK infrastructure projects in a passive fire protection setting. The replicability of the findings to other facets of the sector is untested. It is unknown whether findings would differ if this research was conducted outside the UK or in separate specific context.

In the UK, the momentum towards BIM implementation is driven by the directive to have Level 3 as the standard for government contracts by 2025 to ensure that the benefits of digitisation can be reaped in construction projects, illustrating that there is a move from rhetoric to realising the benefits from implementation of the technology. To aid in achieving this, this study provides an in-depth review of application of M-ICT in infrastructure delivery phase of UK projects. The construction industry is beginning to adopt M-ICT; however, this study reveals that this disruptive change is occurring in an informal and inconsistent manner, often void of clear process and direction. Previous studies identify challenges to the adoption of M-ICT but fail to focus on the disruptive nature that this brings to the sector. To enable the industry to address the current disruptive shift in working practices, it is necessary to identify the challenges requiring redress prior to identifying strategies to address the challenges reported in this study. Subsequently, it is now possible to develop this further and catalogue the various strategies that can now be considered to address the challenges documented. The development of an industry standardised implementation plan for M-ICT would assist all project stakeholders in taking the leap to migrate from a paperbased processes to one which is digitally orientated. The disruptive nature that the migration from paper-based to M-ICT processes results in clear push back and reluctance from the industry; however, given the unsustainable and ineffective current working practices, such migration is not only necessary but essential to continue to drive quality assurance, in this case, in passive fire protection on large infrastructure projects in the UK.

\section{References}

Abanda, F.H., Mzyece, D., Oti, A.H. and Manjia, M.B. (2018), “A study of the potential of cloud/mobile BIM for the management of construction projects", Applied System Innovation, Vol. 1 No. 2, pp. 1-19, doi: 10.3390/asi1020009. 
Alsafouri, S. and Ayer, S.K. (2018), "Review of ICT implementations for facilitating information flow between virtual models and construction project sites", Automation in Construction, Vol. 86, pp. 176-189, doi: 10.1016/j.autcon.2017.10.005.

Arayici, Y. and Aouad, G. (2010), "Building information modelling (BIM) for construction lifecycle management", in Doyle, S.G. (Ed.), Construction and Building: Design, Materials, and Techniques, Construction and Building, Design, Materials, and Techniques, Nova Science Publishers, pp. 99-118.

ASFP (2019), What Is Passive Fire Protection, available at: https://asfp.org.uk/what-is-pfp/ (accessed 12 April 2019).

Azhar, S., Cox, A.J. and Stewart, F. (2015), "Impact of mobile tools and technologies on jobsite operations", 51st ASC Annual International Conference Proceedings, Texas, April 22-25, Texas A\&M University in College Station, pp. 1-8.

Creswell, J.W. (2014), Research Design Qualitative, Quantitative, and Mixed Methods Approaches, 4th ed., SAGE Publications.

Davies, R. and Harty, C. (2013), "Automation in Construction Implementing 'Site BIM': a case study of ICT innovation on a large hospital project", Automation in Construction, Vol. 30, pp. 15-24, doi: 10.1016/j.autcon.2012.11.024.

Eisenhardt, K.M. (1989), "Building theories from case study research", Academy of Management Review, Vol. 14 No. 4, pp. 532-550.

Ern, P.A.S., Kasim, N., Masrom, M.A.N. and Chen, G.K. (2017), "Overcoming ICT barriers in IBS management process in Malaysia construction industry", MATEC Web of Conferences, Vol. 103, pp. 1-10, doi: 10.1051/matecconf/20171030.

European Commission (2015), Construction and Demolition Waste, available at: http//ec.europa.eu/ environment/construction_demolition.htm (accessed 29 April 2021).

Faller, C. and Feldmuller, D. (2015), "Industry 4.0 learning factory for regional SMEs", Procedia CIRP, Vol. 32, pp. 88-91, doi: 10.1016/j.procir.2015.02.117.

Hackitt, J. (2018), Building a Safer Future Independent Review of Building Regulations and Fire Safety: Final Report, Ministry of Housing, Communities and Local Government, London, Crown Copyright, 978-1-5286-0293-8.

Harstad, E., Lædre, O., Svalestuen, F. and Skhmot, N. (2015), "How tablets can improve communication in construction projects", 23rd Annual Conference of the International Group for Lean Construction, Perth, Australia, July 29-31, pp. 391-401.

Hasan, A., Jha, K.N., Rameezdeen, R., Ahn, S. and Baroudi, B. (2019), "Perceived productivity effects of mobile ICT in construction projects", in Mutis, I. and Hartmann, T. (Eds), Advances in Informatics and Computing in Civil and Construction Engineering, Springer, Cham, doi: 10.1007/ 978-3-030-00220-6_20.

HM Government (2017), Building our Industrial Strategy, HM Government Green Paper, London.

HM Government (2013), Construction 2025 - Industrial Strategy: Government and Industry in Partnership, July, Crown Copyright, London.

Hwang, B., Thomas, S., Hass, C. and Caldas, C. (2009), "Measuring the impact of rework on construction cost performance", Journal of Construction Engineering and Management, Vol. 135 No. 3, pp. 187-199.

Kasim, N. (2011), "ICT implementation for materials management in construction projects: case studies", Journal of Construction Engineering and Project Management, Vol. 1 No. 1, pp. 31-36, doi: 10.6106/JCEPM.2011.1.1.031.

Lekan, A., Aigbavboa, C., Babatunde, O., Olabosipo, F. and Christiana, A. (2020), "Disruptive technological innovations ain construction field and fourth industrial revolution in the achievement of sustainable development goal 9", International Journal of Construction Management. doi: 10.1080/156223599.2020.1819522. 
IJBPA 40,3

\section{4}

Liu, T., Mbachu, J., Mathrani, A. and Jones, M.B. (2017), "The perceived benefits of apps by construction professionals in New Zealand”, Buildings, Vol. 7 No. 4, p. 111, doi: 10.3390/buildings7040111.

Love, P.E.D., Matthews, J. and Zhou, J. (2020), "Is it just too good to be true? Unearthing the benefits of disruptive technology", International Journal of Information Management, Vol. 52, pp. 1-7, doi: 10.1016/j.ijinfomgt.2020.102096.

Martínez-Rojas, M., Marín, N. and Vila, M.A. (2016), "The role of information technologies to address data handling in construction project management", Journal of Computing in Civil Engineering, Vol. 30 No. 4, pp. 1-20.

Matthews, J., Love, P.E.D., Heinemann, S., Chandler, R., Rumsey, C. and Olatunj, O. (2015), "Real time progress management: Re-engineering processes for cloud-based BIM in construction", Automation in Construction, Vol. 58, pp. 38-47, doi: 10.1016/j.autcon.2015.07.004.

McKinsey and Company (2017), A Future That Works: Automation, Employment and Productivity, referencing McKinsey \& Company: McKinsey Global Institute, Shenzhen.

Mutesi, E.T. and Kyakula, M. (2011), "Application of ICT in the construction industry in Kampala", Second International Conference on Advances in Engineering and Technology, Dehradun (Uttarakhand), India, July 19th, Vol. 20, pp. 263-269.

Oesterreich, T.D. and Teuteberg, F. (2016), "Understanding the implications of digitisation and automation in the context of Industry 4.0: a triangulation approach and elements of a research agenda for the construction industry", Computers in Industry, Vol. 83, pp. 121-139, doi: 10.1016/ j.compind.2016.09.006.

Prism Environmental (2012), Construction Sector Overview in the UK: Report for the European Commission, available at: http://www.prismenvironment.eu/reports_prism/UK_PRISM_ Environment_Report_EN.pdf (accessed 29 March 2021).

Proverbs, D. and Gameson, R. (2008), Advanced Research Methods in the Built Environment, in Knight, A. and Ruddock, L. (Eds), Blackwell Publishing, Chichester.

Rimmington, A., Dickens, G. and Pasquire, C. (2015), "Impact of information and communication technology (ICT) on construction projects", Organization, Technology \& Management in Construction: An International Journal, Vol. 7 No. 3, pp. 1367-1382, doi: 10.5592/otmcj.2015.3.4.

Sattineni, A. and Schmidt, T. (2015), "Implementation of mobile devices on jobsites in the construction industry”, Procedia Engineering, Vol. 123, pp. 488-495, doi: 10.1016/j.proeng.2015.10.100.

Silverio, M., Donastorg, A., Renukappa, S. and Suresh, S. (2016), "Mobile computing in the construction industry: main challenges and solutions", International Conference in Leadership, Innovation and Entrepreneurship, Dubai, United Arab Emirates, pp. 85-99.

Timico (2018), 5 Ways Digitisation Can Recue Global Waste, available at: https://www.timico.com/fiveways-digitisation-can-reduce-global-waste/.

Tulenheimo, R. (2015), "Challenges of implementing new technologies in the world of BIM - case study from construction engineering industry in Finland", Procedia Economics and Finance, Vol. 21, pp. 469-477.

Yin, R. (2014), Case Study Research Design and Methods, 5th ed., SAGE Publications, Thousand Oaks, CA, ISBN-13: 978-1506336169.

\section{Corresponding author}

John Spillane can be contacted at: John.Spillane@ul.ie

For instructions on how to order reprints of this article, please visit our website:

www.emeraldgrouppublishing.com/licensing/reprints.htm

Or contact us for further details: permissions@emeraldinsight.com 